\title{
A INCLUSÃO QUE ESTÁ NOS QUADRINHOS: COMO OS PERSONAGENS PODEM DIVERTIR E ENSINAR SOBRE AS PESSOAS COM DEFICIÊNCIA
}

\author{
LA INCLUSIÓN EN CÓMICS: CÓMO LOS PERSONAJES PUEDEN DIVERTIRSEY \\ ENSEÑAR SOBRE LAS PERSONAS CON DISCAPACIDAD
}

\author{
THE INCLUSION THAT IS IN COMIC: HOW CHARACTERS CAN ENTERTAIN AND \\ TEACH ABOUT PEOPLE WITH DISABILITIES
}

\author{
Danielle da Silva Pinheiro WELLICHAN ${ }^{1}$ \\ Carla Cristine Tescaro Santos LINO
}

\begin{abstract}
RESUMO: A inclusão de pessoas com deficiência tem sido abordada pelos meios de comunicação sob diversas formas, uma delas é a história em quadrinho. Ora rejeitados, ora aceitos na educação, alguns personagens com deficiência têm sido inseridos e incluídos em histórias já conhecidas e aceitos pelos leitores de diversas idades. Mas será que podem auxiliar no processo de inclusão escolar e social? Acredita-se que sim, pois de forma lúdica, apresentam um universo a ser compreendido, respeitado e possível de ser vivenciado. Por meio de uma breve discussão sobre a temática, construída por materiais impressos e eletrônicos nacionais e internacionais, o presente texto apresenta o histórico dos quadrinhos na educação, e a abordagem da inclusão nas histórias em quadrinhos em seus diversos gêneros em uma leitura inclusiva. Percebe-se que ao olhar para os quadrinhos como um recurso didático e pedagógico há uma variedade de possibilidades a serem exploradas e aproveitadas que podem contribuir para realidades mais inclusivas em ambientes escolares e na sociedade em geral.
\end{abstract}

PALAVRAS-CHAVE: Inclusão escolar. História em quadrinhos. Personagens com deficiência. Deficiência. Leitura inclusiva.

RESUMEN: La inclusión de personas con discapacidad ha sido abordada por los medios de comunicación bajo diversas formas, una de ellas es el cómic. Ahora bien, rechazados, ya aceptados en la educación, algunos personajes con discapacidad han sido insertados $e$ incluidos en historias ya conocidas y aceptadas por los lectores de diversas edades. Pero, ¿pueden ayudar en el proceso de inclusión escolar y social? Se cree que sí, pues de forma lúdica, presentan un universo a ser comprendido, respetado y posible de ser vivenciado. Por medio de una breve discusión sobre la temática, construida por materiales impresos y electrónicos nacionales e internacionales, el presente texto presenta el historial de los cómics

\footnotetext{
${ }^{1}$ Universidade Estadual Paulista "Júlio de Mesquita Filho" (UNESP), Marília - SP - Brasil. Doutoranda em Educação na linha de Educação Especial no Programa de Pós-graduação na UNESP/Marília. Bibliotecária e Pedagoga. Participante do Grupo de Pesquisa Deficiências Físicas e Sensoriais - DeFSen na UNESP, campus de Marília. ORCID: . E-mail:

2 Universidade Estadual Paulista "Júlio de Mesquita Filho" (UNESP), Marília - SP - Brasil. Doutoranda em Educação, na linha de Educação Especial no Programa de Pós-graduação na UNESP/Marília.Professora Bilíngue em SRMI-Área Surdez. Participante do Grupo de Pesquisa Deficiências Físicas e Sensoriais - DeFSen na UNESP, campus de Marília. carlatescaro@yahoo.com.br
} 
en la educación, y el abordaje de la inclusión en los cómics en sus diversos géneros en una lectura inclusiva. Se percibe que al mirar los cómics como un recurso didáctico y pedagógico hay una variedad de posibilidades a ser explotadas y aprovechadas que pueden contribuir a realidades más inclusivas en ambientes escolares y en la sociedad en general.

PALABRAS CLAVE: Inclusión escolar. Historia de los cómics. Personajes con discapacidad. Discapacidad. Lectura inclusiva.

ABSTRACT: The inclusion of people with disabilities has been approached by the media in a variety of ways, one of which is the comic strip. Sometimes rejected, sometimes accepted in education, some disabled characters have been inserted and included in stories already known and accepted by readers of various ages. But can they help in the process of school and social inclusion? It is believed that they can, because in a playful way, they present a universe to be understood, respected and possible to be experienced. Through a brief discussion on the subject, built by national and international printed and electronic materials, the present text presents the history of comics in education, and the approach of inclusion in comic books in discursive textual genre in an inclusive reading. It is noticed that when looking at comics as a didactic pedagogical resource there are a variety of possibilities to be explored and harnessed that can contribute to more inclusive realities in school environments and in society in general.

KEYWORDS: School inclusion. Comic. Characters with disabilities. Deficiency. Inclusive reading.

\section{Introdução}

Nos últimos anos, a inclusão tem sido bastante abordada - embora nem sempre com conceitos corretos ou bons exemplos pela mídia e pelos meios de comunicação - em filmes, novelas, comerciais, documentários, projetos e histórias que trazem personagens com deficiência. Nas histórias em quadrinhos, ou popularmente conhecidos gibis, um universo de boas possibilidades se abriu para a temática, seja sob o olhar de professores, profissionais da Educação e áreas afins, ou de leitores de diversas idades que descobrem na leitura inclusiva, que ser diferente não é um problema de ordem educacional, social ou cultural.

Personagens conhecidos no mundo dos quadrinhos receberam amigos com deficiência e demonstraram uma convivência saudável, com descobertas, empatia, respeito e isso, tornouse um demonstrativo de como essas histórias podem auxiliar na compreensão sobre as deficiências, e como deve ser a convivência e a inclusão delas na sociedade.

Iniciativas interessantes têm sido criadas e disponibilizadas no intuito de orientar de forma divertida e simples, pois retratam em situações do cotidiano, o autismo, a acessibilidade, a cegueira, a amputação, a Síndrome de Down entre outras deficiências. 
Distantes da sala de aula por serem consideradas como prejudiciais ao desenvolvimento intelectual do aluno, foi só na segunda metade do século passado, que as histórias em quadrinhos (HQs) ganharam espaço na área educacional. Estimulada pelo mercado editorial nos anos 80 e 90, novos públicos foram conquistados na crença de que esse gênero atingiria diversas idades, já que se trata de uma leitura autônoma que não exige a intervenção de outra pessoa para compreender as imagens (WOUDA, 2017) e assim, a diversidade temática adentrou o universo dos quadrinhos (VERGUEIRO; RAMOS, 2009).

Essa concepção sobre a HQ de que o gênero não era exclusivo do público infantil, permitiu a presença dos quadrinhos em livros didáticos a partir da década de 80 e colaborou para que a Lei de Diretrizes e Bases (LDB, 1996) ressaltasse a importância da aprendizagem de linguagens contemporâneas e diversificadas para a formação no ensino. Mais tarde, com os Parâmetros Curriculares Nacionais (PCN, 1997; 1998) as HQs foram consideradas como um gênero obrigatório a ser trabalhado pedagogicamente em diferentes disciplinas. Assim, a competência leitora pôde ser trabalhada tanto em língua portuguesa, quanto na disciplina de artes no ensino fundamental, para ilustrar questões em avaliações, ou em atividades em sala de aula de forma lúdica.

Em 2000, os PCN trouxeram ao ensino médio a possiblidade de veicular aspectos da realidade social, com as manifestações artísticas, o que proporcionou condições para reflexão sobre temas sociopolíticos, econômicos e culturais diante de um elemento imagético em conteúdos de História, Geografia e em outras disciplinas, para facilitar a compreensão de temas mais complexos, por ser considerada uma obra rica em simbologia (REZENDE, 2009, p. 126).

A presença de gênero textual discursivo nas salas de aula possibilitou que o Programa Nacional Biblioteca na Escola (PNBE) incluísse as HQs, inicialmente, para o Ensino Fundamental, sob a forma de adaptação de clássicos da literatura, conforme exigência imposta pelo programa, e, posteriormente, para o Ensino Médio. Criado em 1997, foi só em 2006 que as HQs foram incluídas no programa citado, que incluía a compra e a distribuição de livros para as escolas de Ensino Fundamental e Médio, a fim de estimular a leitura de novos conteúdos, despertando, assim, o interesse e o gosto de diversos leitores (RAMOS, 2009).

Ainda conforme Ramos (2009) descreveu, esse incentivo governamental causou uma espécie de evolução desse gênero discursivo, que transitou entre opiniões que a consideravam como inferior e desqualificada, até ser considerada, oficialmente, como uma leitura acessível a diversas fases escolares, e consagrando autores, desenhistas e cartunistas brasileiros. Enfim, 
as HQs deixaram de ser "[...] subversivas ou superficiais para serem oficializadas como política de governo" (VERGUEIRO; RAMOS, 2009, p. 40).

E mesmo diante de questões como a falta de formação técnica de profissionais para seu uso, ou de falta de materiais que de fato explore as potencialidades desse recurso, pode-se considerar que os quadrinhos têm assumido mais uma posição no contexto educacional, o de orientação, no sentido de contribuir para o entendimento da deficiência, e, consequentemente, para demonstrar que a inclusão é possível e necessária.

Mas será que as HQs podem mesmo trazer algum "beneficio" ou alguma verdade sobre a inclusão de pessoas com deficiência? Será que as informações trazidas nas histórias podem ser aproveitadas para tratar um assunto dessa natureza? É justamente neste contexto que o presente texto se desenvolveu, a fim de propor uma discussão sobre a temática da inclusão presente nas HQs. Por meio de uma breve discussão sem recorte temporal (devido a evolução histórica do tema) e advinda de material impresso e eletrônico, de origem nacional e internacional, foi proposta a reflexão sobre esse recurso didático e pedagógico para que possibilidades sejam discutidas, exploradas, aproveitadas e que possam contribuir para realidades mais inclusivas e possíveis, não só no ambiente escolar, como em toda a sociedade.

\section{Os Quadrinhos e a Inclusão}

Conforme Vergueiro e Ramos (2009, p. 40) descreveram, quando se fala em HQs, trata-se de leitura e

Leitura não é só de livro. Leitura é tudo. Como já dizia o educador Paulo Freire (1988), "a leitura do mundo precede a leitura da palavra". Assim pode-se dizer que uma leitura sempre é o caminho para outras mais, numa espiral sem começo ou fim. Um outdoor leva a uma fotografia, que leva a um vídeo, que leva a um programa de televisão, que leva a um desenho animado, que leva a uma história em quadrinhos, que leva a um livro, que leva a um filme, que leva a um outdoor anunciando a estreia do longametragem.

Nesse movimento cíclico proporcionado pela leitura, as HQs ganham vida nas telas, mas também se mantêm nas páginas impressas. E embora não possua uma produção cientifica numerosa ainda, apresenta-se como uma temática que desperta atenção, traz oportunidades para o aprendizado e a vivência em qualquer idade.

Sua origem remete ao início da civilização, com as inscrições rupestres nas cavernas, em uma espécie de mural, onde retratavam a necessidade do homem em se expressar e narrar os acontecimentos por meio de registros desenhados (BIBE-LUYTEN, 1989). 
Com o passar do tempo e o aperfeiçoamento das técnicas de desenho e impressão, as HQs ganharam suportes, temáticas, contextos e enfoque variados. Foi no fim do século passado que elas ganharam espaço como meio de comunicação de massa, apareceu em jornais, no formato de desenhos satíricos e caricaturais, e, posteriormente, apresentou núcleos familiares e políticos (VERGUEIRO, 2005).

A primeira história considerada em quadrinhos do mundo é a Histoire de M. Vieux Bois, do suíço Rodolphe Töpffer, editada em 1827. Tempos mais tarde, o italiano Angelo Agostini, em território brasileiro, apresentou suas publicações em revistas que se iniciaram no dia 31 de janeiro de 1869, data em que se comemora o Dia Nacional dos Quadrinhos. Posterior a Töpffer, veio a publicação de The Yellow Kid, por Richard Felton Outcault, publicada em 1896 em uma tirinha dominical e disputada pelos maiores nomes do jornalismo norte-americano no período (LOPES, 2017).

Em 2017 a Câmara Brasileira do Livro (CBL), organizadora do Prêmio Jabuti, anunciou que uma categoria para histórias em quadrinhos seria incluída em sua próxima edição, decisão tomada após a entrega de um abaixo-assinado para a CBL e apoiada por quadrinistas prestigiados como Laerte Coutinho, Marcello Quintanilha e os irmãos Fábio Moon e Gabriel Bá, com mais de duas mil assinaturas (LOPES, 2017).

Segundo Vergueiro em entrevista ao Jornal da Universidade de São Paulo - USP (LOPES, 2017, não paginado),

História em quadrinhos é história em quadrinhos. E literatura é literatura. Histórias em quadrinhos são uma manifestação artística com dois códigos: a imagem e o texto", justifica o professor. "A junção desses códigos com os recursos característicos das HQs (balões de fala, onomatopeias etc.) faz com que a forma de narrar dos quadrinhos seja única". Mesmo que as HQs mantenham uma relação com a literatura através do texto escrito, elas também têm uma forte conexão com o cinema, o teatro e a ilustração.

Pesquisas acadêmicas têm apresentado bons índices de crescimento por meio de eventos como as Jornadas Internacionais de Histórias em Quadrinhos, promovidas pelo Observatório de HQs da Escola de Comunicação (ECA) da Universidade de São Paulo (USP), disciplinas ofertadas aos cursos de graduação e outros núcleos de pesquisa localizados na Universidade Federal do Rio de Janeiro (UFRJ), na Universidade Federal da Paraíba (UFPB) e na Associação de Pesquisadores da Arte Sequencial (Aspas), sediada em Leopoldina, Minas Gerais, com pesquisas que apresentam o universo dos quadrinhos com possibilidades para utilização em diversos áreas e para públicos de todas as idades. 
O fato é que o percurso histórico das HQs foi marcado por momentos de negação e rejeição até chegar aos dias em que se tornaram reconhecidas e consideradas pela educação. Faz parte de todo esse contexto a variação das temáticas tratadas nessas histórias, e assim a inclusão chega no momento em que movimentos em sua defesa (tanto da inclusão quanto das HQs) foram crescendo na sociedade.

A partir do momento em que a inclusão se tornou "visível" e necessária de discussão (por meio de marcos históricos como a Declaração de Jontien e de Salamanca, as discussões a respeito da Educação Inclusiva e as legislações estabelecidas no Brasil), os quadrinhos buscaram meios de também abordar o assunto, e a forma encontrada para isso, foi por meio de histórias com personagens que apresentavam alguma deficiência com uma vida aparentemente "comum".

A realidade da inclusão escolar vigente aponta a necessidade de uma prática pedagógica viável usando histórias em quadrinhos, instigando o desenvolvimento afetivo, cognitivo e comportamental, para favorecer a inclusão na escola. Tendo como base a relevância da discussão e, necessariamente, o debate e, dessa forma, oportuniza novas formas de aprendizado ao abranger o aluno como um todo, suas habilidades e potencialidades referentes à acessibilidade nos ambientes escolares, pois essa é a condição imprescindível para a construção de uma educação inclusiva de que se pressupõem novas exigências às questões da escola, da aula e do professor (STRADA, 2016, p. 3)

Conforme Caldeira (2018, p. 10) descreveu, desenvolver atividades criativas, não se restringindo ao já conhecido, além de explorar as linguagens verbais e não verbais, permitem a aplicação de novos materiais em sala de aula. Nesse sentido, "O diferencial está na forma como o professor utiliza o material e no que é solicitado para que os alunos desenvolvam a partir dele".

E se trabalhar a inclusão nas escolas demanda um trabalho de conscientização, por que não utilizar um recurso lúdico que pode atingir a toda comunidade?

Nesta perspectiva, as HQs podem favorecer o trabalho com as atitudes sociais na busca pela inclusão de pessoas com deficiência nas escolas, nas comunidades, na sociedade em geral, porque embora existam as leis, muito há que ser feito para que o pertencimento dessas pessoas seja maior do que a exclusão. 


\section{Personagens com Deficiência nos Quadrinhos}

O desenhista criador da Turma da Mônica, Maurício de Sousa, por meio de seu Instituto Cultural, publicou algumas histórias que trazem como personagens pessoas com deficiência, no intuito de orientar de forma simples e lúdica seus leitores.

Há 60 anos, Mônica, Magali, Cebolinha, Cascão, Franjinha (que junto com o cãozinho Bidu, foram os primeiros personagens criados em 1959), Jeremias, Titi, Anjinho entre outros personagens, fazem sucesso com histórias vivenciadas pelas crianças do bairro do Limoeiro em muitas aventuras. Chico Bento representa outra turma, que vive no campo, mas que algumas vezes se mistura com a Turma da Mônica. Também há a Turma do Penadinho, do Horácio, da Tina, do Astronauta, entre outras criações baseadas na infância do próprio Mauricio de Souza.

Nos anos 2000, dois novos personagens foram trazidos para as histórias: Luca, um garoto cadeirante e Dorinha, uma menina com deficiência visual, cuja inspiração foi Dorina de Gouvêa Nowill, uma educadora, filantropa e administradora brasileira que trabalhou incansavelmente para a criação de instituições, leis e campanhas em prol dos deficientes visuais, e que teve o seu trabalho reconhecido e premiado.

Luca é um menino que demonstra gostar de esportes, principalmente o basquete e por esse motivo ganhou o apelido da turma de "Da Roda" e "Paralaminha", devido ao gosto pela banda "Os Paralamas do Sucesso". Já a Dorinha, é uma menina gentil e querida que usa óculos escuros, e tem um cão-guia da raça labrador que atende pelo nome de Radar e, algumas vezes, aparece com uma bengala.

Personagens como os citados a seguir (Figura 1), foram baseados em pessoas reais que o desenhista conheceu, ou que são referências na deficiência e se apresentam nas histórias em meio aos outros personagens já conhecidos. Trazem ao longo da história, informações a respeito de sua condição, necessidades e meios de auxílio para orientar as pessoas sem deficiência diante delas. 
Figura 1 - Personagens com deficiência que foram incluídos na Turma da Mônica

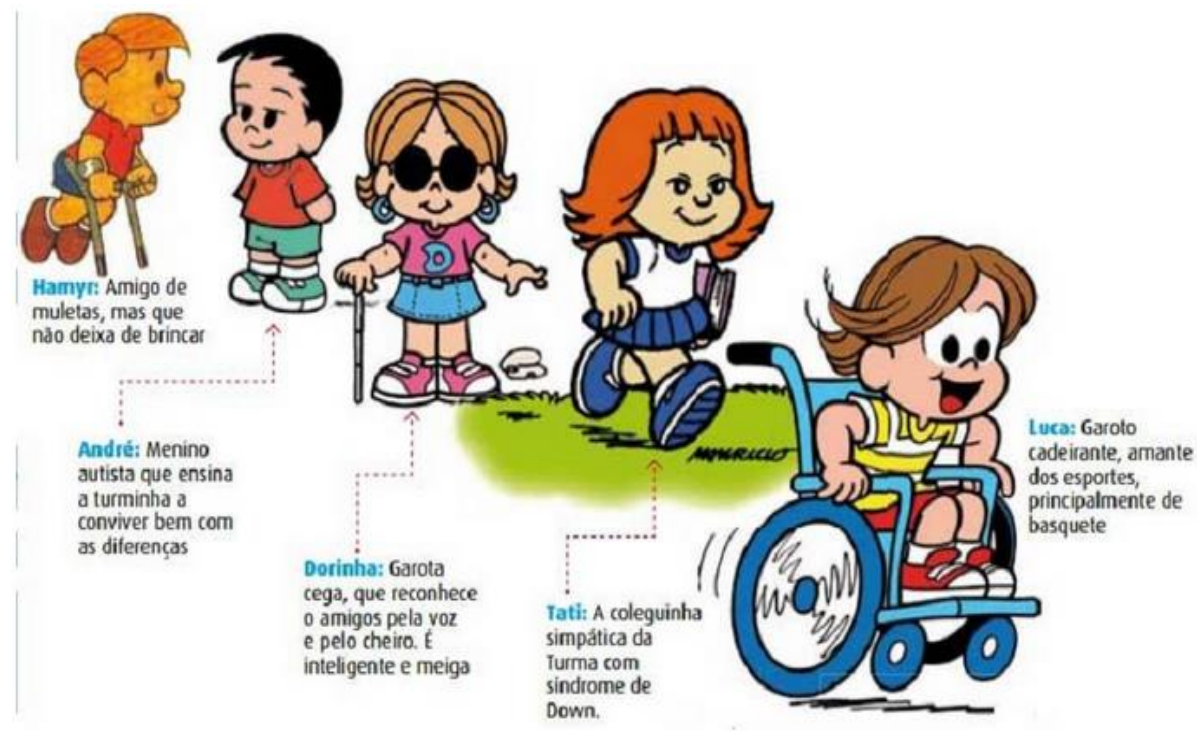

Fonte: Portal Deficiente Ciente (GARCIA, 2018)

Posteriormente, chegou o André, irmão de uma amiga de Magali e que retrata uma criança com autismo; Tati (Tatiana), uma menina com Síndrome de Down com olhos pequenos e puxados se aproximando da imagem real da síndrome; Humberto, um amigo que não fala, só emite murmúrios, mas não há confirmações de que ele seja mudo de fato; e Hamyr, considerado o primeiro amigo com deficiência (física) na turma ainda na década de 80 e que se mostrava bastante habilidoso com o uso das muletas. Segundo informações publicadas no portal Fandom Quadrinhos, que hospeda a página da Turma da Mônica Wiki ([19--], não paginado), a história, de autoria de Rubens Kiyomura objetivou

[...] demostrar como o preconceito, que era bastante visível naquela época, e é até hoje, é ridículo e insensato. Isto porque, apesar das dificuldades, um deficiente físico tem total possibilidade de realizar tarefas e obrigações; dessa forma, nasceu a ideia de uma historinha em que um garoto de muletas gostaria de brincar de futebol com o Cebolinha e o Cascão, mas acaba sendo impedido por sua Mãe, que tem receio de que ele possa se machucar por conta de sua "fragilidade", mas que depois se arrepende de suas ações e deixa o filho viver sua vida.

Mesmo não sendo presenças frequentes nas HQs de Mauricio de Souza, esses personagens aparecem em campanhas publicitárias e números especiais (figura 2), numa realidade bem próxima ao que se deseja quando se fala na convivência de crianças com e sem deficiência. 
A turma da Mônica é um grupo de personagens que vivem e agem, nas historinhas, como crianças reais. São como nossos filhos ou conhecidos. E sem dúvida todos nós temos amigos com algum tipo de deficiência, num convívio harmônico e dinâmico. Assim aprendemos as regras da inclusão. E por que não repetirmos nos quadrinhos nossas experiências nesse sentido? Provavelmente estaremos sugerindo comportamento semelhante aos nossos leitores. Algum bom resultado deve advir ${ }^{3}$.

Em um Congresso de Pediatria de São Paulo (2019) foi lançado o comunicado sobre o surgimento de mais um personagem na escola da turma, o Edu, com Distrofia Muscular de Duchenne. Segundo Mauricio de Souza apresentou, é uma criança que gosta de desenhar, é esperto, tem um cachorro chamado Sapeca, convive com a doença e é parte de um dos projetos editoriais “[...] da Maurício de Sousa Produções com o laboratório Sarepta, chamado "Cada passo importa", para trazer o assunto para mais perto do dia a dia das famílias e das crianças" (ONGARATTO, 2019, s/p).

Figura 2 - Algumas capas das HQs criadas com personagens com deficiência
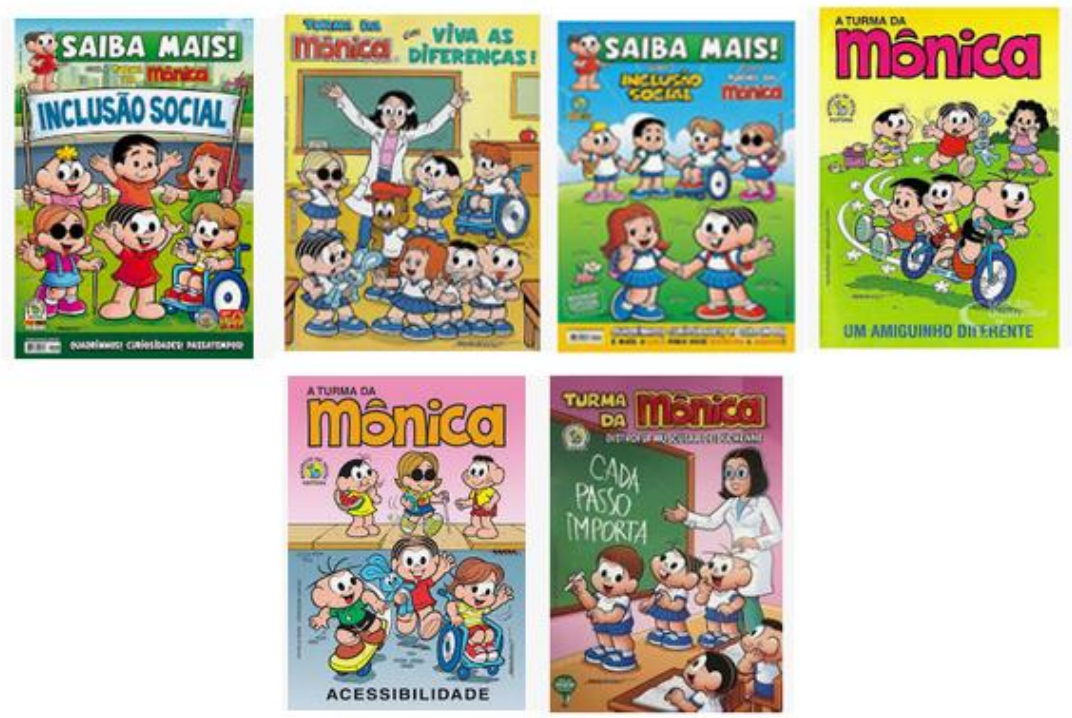

Fonte: Exemplares acervo pessoal das autoras

Se as HQs podem trazer experiências de vivências importantes para as pessoas sem deficiência, para as que possuem alguma, pode ser uma forma de sentir-se representado pelo personagem. Nos fragmentos abaixo (figura 3), Edu relembra o dia vivido e demonstra o quão satisfeito ficou em ser compreendido e apoiado pelo amigos na escola.

${ }^{3}$ Relato de Mauricio de Souza em entrevista à Fundação Bunge, publicada por Ricardo Shimosakai na página Turismo Adaptado. Disponível em: https://turismoadaptado.com.br/deficiencia-em-quadrinhos-nos-personagensdo-desenhista-mauricio-de-sousa/ Acesso em: 22 maio 2019. 
Figura 3 - O sentimento de Edu
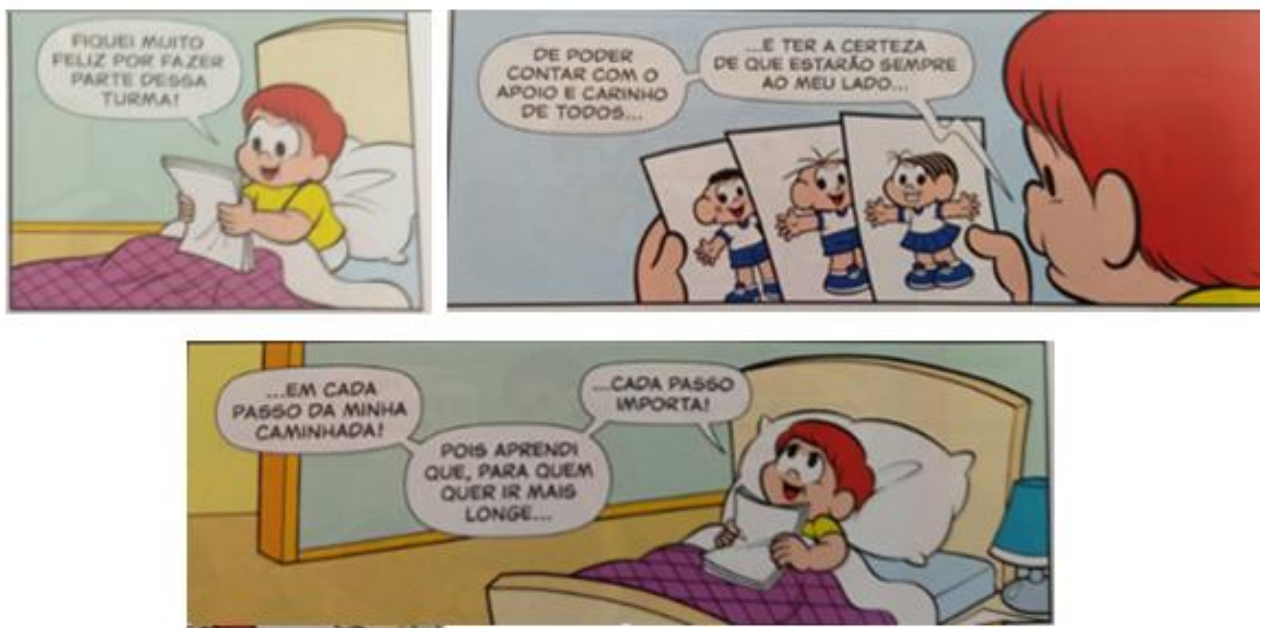

Fonte: HQs Turma da Mônica - Distrofia Muscular de Duchenne (2019, p. 22)

Outro autor/desenhista que também possui trabalhos que visam à orientação de deficiências e síndromes é o cartunista Ziraldo. Em 2013 elaborou junto à sua equipe de produção, a cartilha sobre o autismo, que foi disponibilizada gratuitamente na internet e distribuída em postos e escolas.

Figura 4 - Cartilha sobre o Autismo

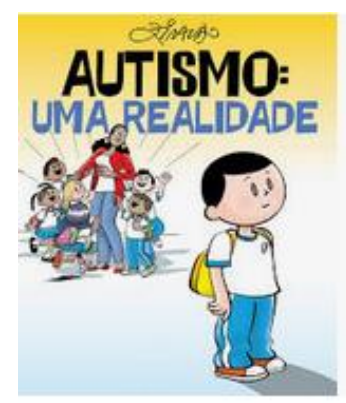

Fonte: Ziraldo (2013)

A cartilha foi desenvolvida com o objetivo de auxiliar pais, profissionais da educação e da saúde na identificação de sinais do Transtorno do Espectro Autista (TEA) em crianças desde os primeiros momentos de vida ${ }^{4}$, a fim de evitar a discriminação e incentivar o acolhimento e a compreensão das características desse transtorno no indivíduo.

\footnotetext{
${ }^{4}$ Embora seu formato seja mais próximo ao livro infantil não sendo a proposta deste artigo, traz a questão do personagem e da deficiência, abordados ao longo do texto e por isso incluído.
} 
A Turma da Febeca (figura 5) criada pelo cartunista Victor Klier (que pertenceu à equipe de Ziraldo, daí os traços familiares para os conhecedores da arte) em 2006, cuja personagem principal é a Febeca, uma menina adolescente que utiliza cadeira de rodas devido à paraplegia causada por uma lesão medular. Toda uma turma foi idealizada e inspirada na vida de duas cadeirantes (ou usuárias de cadeiras de rodas), com 15 e 17 anos respectivamente. $\mathrm{Na}$ turma, vários dos personagens possuem deficiência e aparecem em situações que questionam a acessibilidade e questionam seus direitos como cidadãos.

Figura 5 - Turma da Febeca

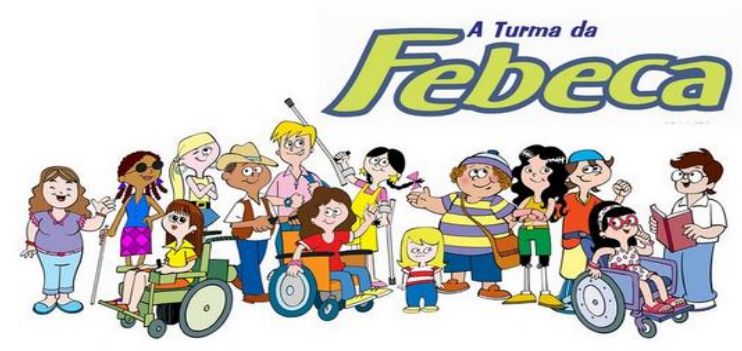

Fonte: Deficiente Ciente (GARCIA, 2010)

Nessa turma, há personagens com deficiências variadas, como as descritas no quadro a seguir (figura 6). 
Figura 6 - Turma da Febeca

Febeca, a "lider", descrita como uma adolescente dinâmica e alegre que não
raramente vai para a diretoria por causa das bagunças (que segundo seu criador, não
comprometem seu desempenho nas disciplinas) na aula.




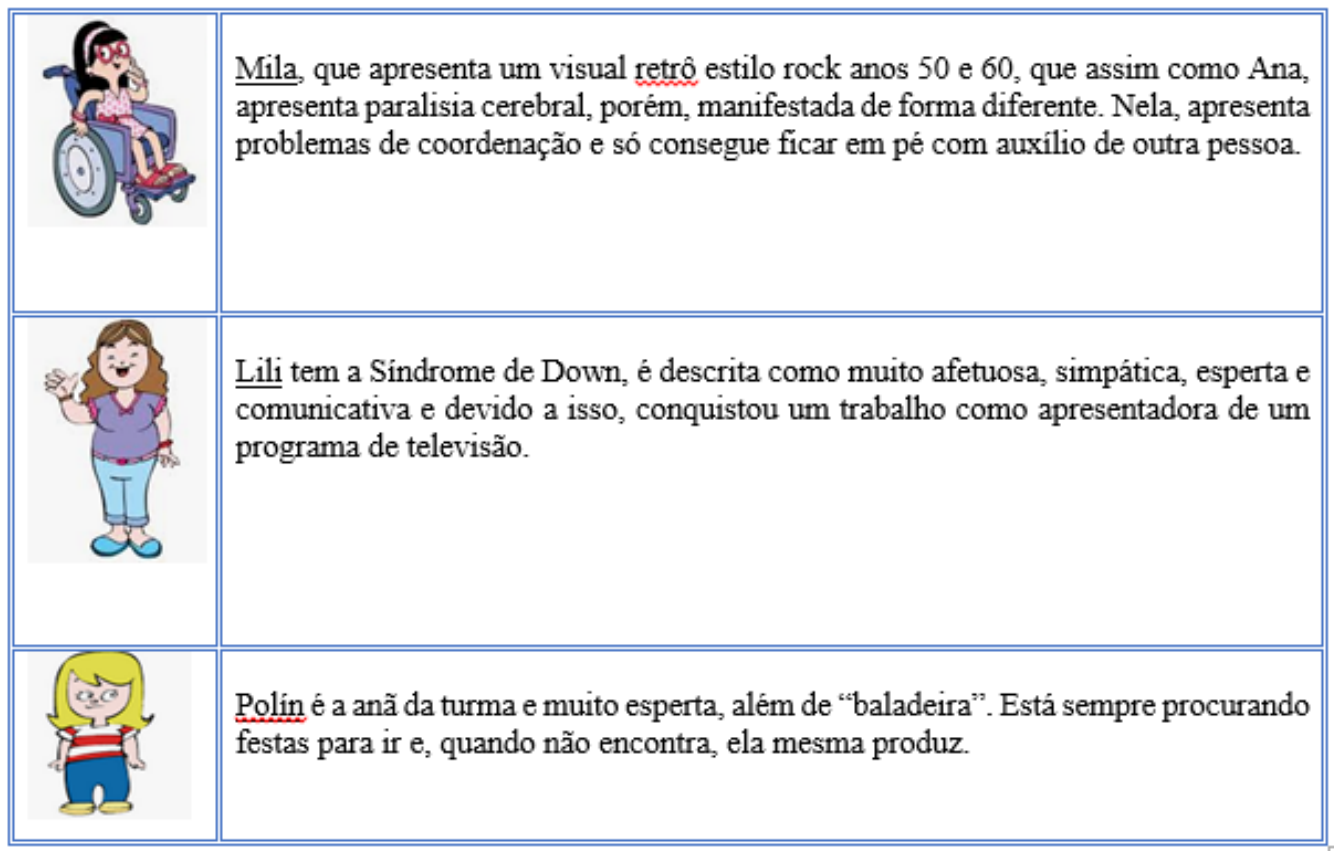

Fonte: Elaborado pelas autoras

(Texto baseado em descrições do cartunista Victor Klier)

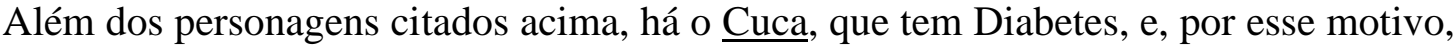
teve de aprender sobre alimentação controlada e, embora tenha habilidade culinária, não pode provar de suas descobertas gastronômicas. É descrito como tímido e sensível, bom nas aulas de matemática e devido ao fato de estar um pouco acima do peso, foge das aulas de Educação Física; Dudu, esperto e intuitivo, sofre de Transtorno Obssessivo Compulsivo (TOC) e por isso perde algumas oportunidades; $\underline{\text { Jana, }}$ coleciona lenços devido à queda de cabelo com o tratamento contra o câncer e adora receber os amigos em casa; e Beto, um adolescente que gosta de futebol e sair com os amigos, mas possui uma rígida disciplina devido ao fato de ser soropositivo e precisar controlar o HIV (SOUZA, 2019).

Para as pessoas sem deficiência, a Turma da Febeca apresenta situações vivenciadas que podem trazer a reflexão sobre diversos aspectos, desde a convivência na escola, nas ruas, até questões que trabalham denúncias de infrações e as legislações inclusivas. Para as pessoas com deficiência é possível se trabalhar a autoestima, ao se reconhecerem e perceberem experiências e posicionamentos.

Quadrinhos com histórias mais "adultas", foram criados por um grupo de amigos (em Curitiba, PR) trazendo mais temas relativos ao "homem" (aceitação, descobertas, potencial de transformação) do que a acessibilidade propriamente dita. 
Figura 7 - Tirinha dos "Super Normais"

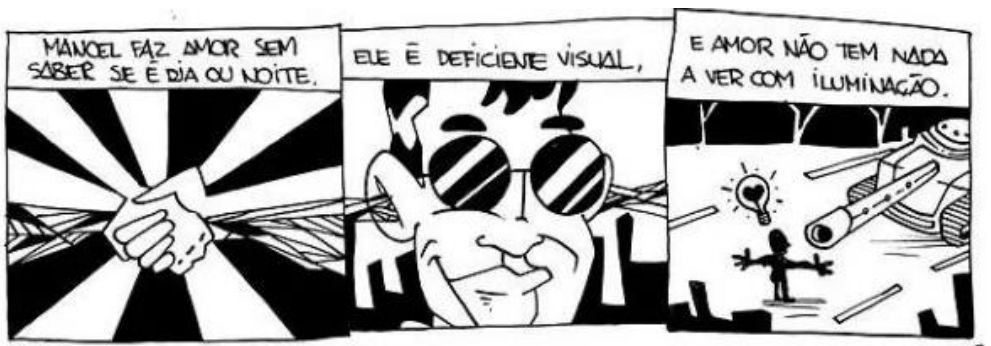

Fonte: Reportagem cedida ao Portal G1 (DIONISIO, 2012)

Mais recentemente, em uma série elaborada por uma revista popular, utilizou os quadrinhos para retratar cenas do cotidiano vivenciadas pelas pessoas com deficiência.

[...] é justamente sobre as sutilezas da falta de informação que queremos discutir com a série "Um dia na vida": muitas vezes não sabemos que nossas atitudes ofendem, interferem na liberdade individual do outro ou que ignoramos a voz de uma parcela da população que quer e merece ser tratada com dignidade. Eles não são excepcionais, especiais, aleijados, incapazes ou heróis: são pessoas com algum tipo de deficiência que querem levar uma vida autônoma e livre. Pedir respeito, acessibilidade e inclusão não tem nada a ver com mimimi (CARBONARI, 2017, s/p).

$\mathrm{Na}$ série (figura 8), os quadrinhos buscam orientar sobre a não necessidade de se referir às pessoas com deficiência no diminutivo ou com frases curtas, infantilizando ou menosprezando a opinião do sujeito. Questões relacionadas à vida amorosa também são ilustradas, alertando sobre as ofensas que podem ser geradas com suposições desagradáveis. Assim como um aparente "elogio" ao falar de superação, pode não ser bem recebido, pois tratar alguém que possui deficiência como um herói “[...] é presumir que a sociedade pode se isentar da responsabilidade de incluí-la. Afinal, por essa lógica, ela tem "super poderes"” (CARBONARI, 2017, não paginado)

A questão do julgamento diante de deficiências que não se mostram "visíveis" também é citada, o que compreende as pessoas amputadas que utilizam prótese, ou que possuem perdas auditivas e/ou surdez.

O uso de algo que está reservado à pessoa com deficiência (banheiro, vaga de estacionamento, assentos reservados) pode representar situações complicadas que impedem o livre acesso e também é abordada na série. 
Figura 8 - Série "Um dia na vida"
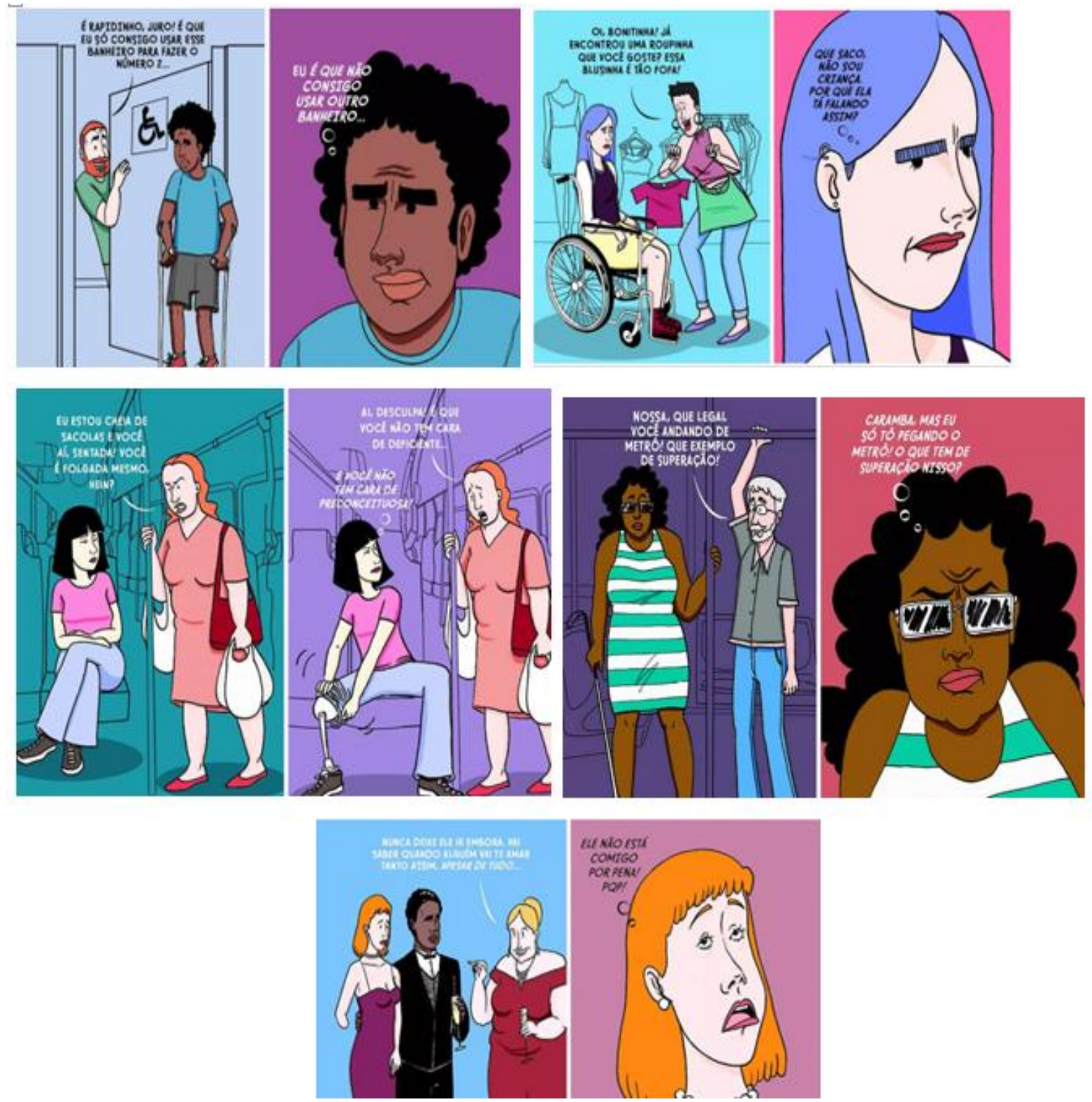

Fonte: Revista Super Interessante (CARBONARI, 2017).

Percebe-se, diante do exposto, que a deficiência pode ser retratada sob diferentes formas, e o uso das HQs contribuem para ilustrar de forma mais lúdica aspectos que exigem compreensão para melhores experiências. Acessíveis para qualquer idade, tornou-se um recurso de comunicação viável para ser utilizado em qualquer segmento da sociedade, seja com personagens existentes ou elaborações próprias e particulares.

Mesmo que tenha vivido por um longo tempo como algo marginalizado, é fato que os quadrinhos podem trazer reflexões, aprendizados com informações que geram conhecimento e práticas saudáveis para pessoas com ou sem deficiência. Acredita-se que, com maiores investimentos, os projetos citados aqui e outros existentes podem ser mais divulgados e 
disponibilizados para que a sociedade, com o objetivo de conhecimento e informação de forma lúdica para informar e divertir.

\section{Considerações finais}

A linguagem verbal, que se manifesta por meio de diálogos, e a não verbal, que se manifesta por meio de balões de diversos formatos e classificações expressos por personagens presentes nas HQs, permitem que os signos cumpram o papel de interpretações da realidade que permitirão ao leitor, uma competência leitora capaz de compreender o significado no processo de ler, sobre a realidade presente em uma sociedade.

A singularidade do gênero discursivo HQs pode ser considerada ampla e não se esgota, devido ao seu valor para aprendizagens no contexto escolar desde a história primitiva, onde os homens dessa época utilizavam desenhos para a comunicação de mensagens, representações da natureza, cultos religiosos entre outros momentos que nos permitem compreender a representação do seu meio de vida e sobre diversos assuntos e contribuir com todas as disciplinas.

As HQs eram vistas somente como entretenimento, porém, a LDB valorizou esse tipo de leitura na formação do leitor no contexto escolar, de forma sistemática, com a concepção dos Parâmetros Curriculares Nacionais, pois os estudantes se interessavam pelos quadrinhos e a união de palavras e imagens permitiam uma leitura mais eficiente, e um alto nível de informação, auxiliando no desenvolvimento de hábitos de leitura. O enriquecimento do vocabulário dos estudantes também foi percebido, bem como o conhecimento globalizado, em qualquer nível de escolaridade, em qualquer tema e disciplina, permitindo ao leitor pensar e imaginar as diversas situações proporcionadas em cada história, edificando, assim, o conhecimento.

$\mathrm{Na}$ criação de Maurício de Sousa, o cartunista brasileiro, surgem personagens com deficiências que foram baseados em pessoas reais conhecidas, que apresentam, no decorrer das histórias, informações sobre as suas condições, limitações, necessidades e meios de auxílio, com uma proposta que pode ser considerada inclusiva para a sociedade brasileira, ainda tão exclusivista. Assim, como ele, outros profissionais surgiram e novos personagens surgiram enriquecendo as HQs com uma variedade de histórias.

As experiências vividas pelos personagens com deficiências podem representar o leitor com deficiência na vida real e sentir que outros leitores podem compreender que as diferenças individuais não devem ser razões para a exclusão, ou para ofender e interferir na liberdade individual da pessoa com deficiência, e tratam de seus direitos como cidadãos, sendo possível 
proporcionar a reflexão de uma sociedade, atingindo todos os tipos de leitores de forma lúdica e prazerosa.

Diante do exposto, não se esgota a discussão sobre os quadrinhos e as pessoas com deficiência e espera-se que novos estudos possam surgir, assim como espera-se que projetos que apresentem essa temática sejam "abraçados" pelo mercado editorial e novas histórias e personagens possam trazer informação, diversão e conhecimento para todas as idades.

\section{REFERÊNCIAS}

BIBE-LUYTEN, S. M. (Org). Histórias em Quadrinhos: Leitura Crítica. São Paulo: Edições Paulinas, 1989.

BRASIL. Secretaria de Educação Fundamental. Lei de Diretrizes e Bases da Educação: Lei 9.394/96. 6. ed. Rio de Janeiro: DP\&A, 2003.

BRASIL. Secretaria de Educação Fundamental. Parâmetros Curriculares Nacionais. Brasília: MEC, 1997. $10 \mathrm{v}$.

CALAZANS, F. M. A. História em quadrinhos na escola. 2. ed. São Paulo: Paulus, 2005.

CALDEIRA, B.A.S.L.M. O uso pedagógico das histórias em quadrinhos no ensino de português para estrangeiros. In: Jornadas Internacionais de Histórias em Quadrinhos, 5., 2018, Escola de Comunicação e Artes, ECA-USP, SP. Anais [...] SP: ECA, 2018. p. 1-11.

Disponível em:

http://www2.eca.usp.br/anais2ajornada/anais5asjornadas/artigos.php?artigo=q_educacao/brizz ida_caldeira.pdf\&jornada=5. Acesso em: 3 jun. 2019.

CARBONARI, P. Um dia na vida de... uma pessoa com deficiência física. Ofensivas que elas passam no dia a dia delas e desenhamos para você. Super Interessante, Comportamento, publicado em: 28 set. 2016. Disponível em:

https://super.abril.com.br/comportamento/um-dia-na-vida-de-uma-pessoa-com-deficienciafisica/. Acesso em: 21 jun. 2019.

DIONISIO, B. Amigos criam tirinha para falar sobre deficiência física e ser humano. Portal G1, 20 out. 2012. Disponível em: http://g1.globo.com/pr/parana/noticia/2012/10/amigoscriam-tirinha-para-falar-sobre-deficiencia-fisica-e-ser-humano.html. Acesso em: 20 maio 2019.

GARCIA, V. Histórias em quadrinhos ensinam como lidar com as diferenças. Deficiente Ciente - O blog da inclusão e cidadania. 26 maio 2018. Disponível em: https://www.deficienteciente.com.br/historias-em-quadrinhos-ensinam-como-lidar-com-asdiferencas.html. Acesso em: 30 maio 2019.

LOPES, L. Histórias em quadrinhos vivem bom momento no Brasil, diz docente: inclusão de histórias em quadrinhos no Prêmio Jabuti valoriza produção nacional, afirma professor da USP. Jornal da USP, 12 maio 2017. Disponível em: https://jornal.usp.br/cultura/historiasem-quadrinhos-vivem-bom-momento-no-brasil-diz-docente/. Acesso em: 12 maio de 2019. 
ONGARATTO, S. Distrofia muscular de Duchenne: Turma da Mônica ganha personagem com a doença. Revista Crescer, 27 mar. 2019. Disponível em:

https://revistacrescer.globo.com/Voce-precisa-saber/noticia/2019/03/distrofia-muscular-deduchenne-turma-da-monica-ganha-personagem-portador-da-doenca.html. Acesso em: 2 jun. 2019.

REZENDE, L. A. de. Leitura e Formação de Leitores: Vivências Teórico Práticas. Londrina: Eduel, 2009.

SOUZA, B. Cartunista cria quadrinhos com personagens cadeirantes. Portal Viva Mulher, [s.d.]. Disponível em: https://vilamulher.com.br/familia/filhos/cartunista-cria-quadrinhoscom-personagens-cadeirantes-14759.html. Acesso em: 4 maio 2019.

STRADA, S.A.C. Práticas inclusivas na escola por meio das histórias em quadrinhos. Os desafios da escola pública paranaense na perspectiva do professor PDE. Cadernos PDE, v. 1, Disponível em:

http://www.diaadiaeducacao.pr.gov.br/portals/cadernospde/pdebusca/producoes_pde/2016/20 16_artigo_edespecial_uenp_selmaaparecidacapelinstrada.pdf. Acesso em: 2 jun. 2019.

RAMOS, P. A leitura dos quadrinhos. São Paulo: Contexto, 2009.

TURMA DA MONICA WIKI. Hamyr. Portal da Comunidade Fandon Quadrinhos. [s.d.]. Disponível em: https://monica.fandom.com/pt-br/wiki/Hamyr Acesso em: 4 maio 2019.

VERGUEIRO, W.; RAMOS, P. Quadrinhos na educação: da rejeição à prática. São Paulo: Contexto, 2009.

VERGUEIRO, W. A linguagem dos quadrinhos: uma "alfabetização necessária. In: RAMA, A.; VERGUEIRO, W. (Org.). Como usar as histórias em quadrinhos na sala de aula. 2. ed. São Paulo: Contexto, 2005. p. 7-30.

WOUDA, J. Zeven Redenen om je kind strips te laten lezen. Publicado em: 25 ago. 2017. Disponível em: https://www.heutinkvoorthuis.nl/nl/7-redenen-om-je-kind-strips-te-latenlezen/news/81/. Acesso em: 13 jun. 2019.

ZIRALDO. Autismo: uma realidade. Texto de Gustavo Luiz e arte de Miguel Mendes, Marco e Fábio Ferreira. Out. 2013. Disponível em:

http://www.mpsp.mp.br/portal/page/portal/cao_civel/cartilha-ziraldo-autismo-umarealidade.pdf. Acesso em: 10 abr. 2019.

\section{Como referenciar este artigo}

WELLICHAN, D. S. P.; LINO, C. C. T. S. A inclusão que está nos quadrinhos: como os personagens podem divertir e ensinar sobre as pessoas com deficiência. Doxa: Rev. Bras. Psico. e Educ., Araraquara, v. 21, n. 1, p. 44-61, jan./jun. 2019. e-ISSN: 2594-8385. DOI: https://doi.org/10.30715/doxa.v21i1.12693 